\title{
Review Article \\ The Role of Glucosamine-Induced ER Stress in Diabetic Atherogenesis
}

\author{
Daniel R. Beriault ${ }^{1,2}$ and Geoff H. Werstuck ${ }^{1,2,3}$ \\ ${ }^{1}$ Thrombosis and Atherosclerosis Research Institute, McMaster University, 237 Barton Street East, Hamilton, ON, Canada L8L $2 X 2$ \\ ${ }^{2}$ Department of Biochemistry and Biomedical Sciences, McMaster University, Hamilton, ON, Canada L8N $3 Z 5$ \\ ${ }^{3}$ Department of Medicine, McMaster University, Hamilton, ON, Canada L8N $3 Z 5$
}

Correspondence should be addressed to Geoff H. Werstuck, geoff.werstuck@taari.ca

Received 29 July 2011; Accepted 27 November 2011

Academic Editor: Muthuswamy Balasubramanyam

Copyright ( 2012 D. R. Beriault and G. H. Werstuck. This is an open access article distributed under the Creative Commons Attribution License, which permits unrestricted use, distribution, and reproduction in any medium, provided the original work is properly cited.

Cardiovascular disease (CVD) is the major cause of mortality in individuals with diabetes mellitus. However the molecular and cellular mechanisms that predispose individuals with diabetes to the development and progression of atherosclerosis, the underlying cause of most CVD, are not understood. This paper summarizes the current state of our knowledge of pathways and mechanisms that may link diabetes and hyperglycemia to atherogenesis. We highlight recent work from our lab, and others', that supports a role for ER stress in these processes. The continued investigation of existing pathways, linking hyperglycemia and diabetes mellitus to atherosclerosis, and the identification of novel mechanisms and targets will be important to the development of new and effective antiatherosclerotic therapies tailored to individuals with diabetes.

\section{Introduction}

Worldwide, cardiovascular disease (CVD) is the leading cause of premature death in both men and women. Risk factors for CVD include abnormal lipid levels, smoking, hypertension, abdominal obesity, stress, sedentary lifestyle, and diabetes mellitus [1]. While the incidence of CVD has declined in many developed countries, this trend is expected to reverse in the near future [2]. This is largely due to the dramatic, worldwide increase in the incidence of diabetes mellitus. Driven by changes in lifestyle and an escalating rate of obesity, the number of individuals with diabetes may already be as high as 350 million [3,4]. Diabetes mellitus is a major, independent risk factor for cardiovascular disease (CVD), and individuals with diabetes are 2 to 3 times more likely to die from $\mathrm{CV}$ causes than people with no history of diabetes, even after controlling for other CV risk factors [59]. These individuals are also at increased risk of diseases that are associated with CVD and atherosclerosis including hypertension and renal failure. Ultimately, this translates to a CV mortality rate in diabetic patients of approximately $75 \%$ $[6,7]$. The increasing incidence of diabetes means that the global burden of this chronic disease on health care resources will continue to rise for the foreseeable future.

It is not clear why individuals with diabetes are predisposed to CVD. Recent reports from clinical trials examining the effects of intensive blood glucose lowering on CV risk, including ACCORD (Action to Control Cardiovascular Risk in Diabetes) [10], ADVANCE (Action in Diabetes and Vascular Disease: Preterax and Diamicron MR Controlled Evaluation) [11], UKPDS (United Kingdom Prospective Diabetes Study) [12], and VADT (Veterans Affairs Diabetes Trial) [13], suggest that the relationship between hyperglycemia and CVD is complex. Despite a vast amount of research, currently available treatments show only limited $\mathrm{CV}$ benefit and CVD continues to be the major cause of mortality.

There is a strong correlation between hyperglycemia and both micro- and macrovascular disease [14-18]. The negative effects of elevated glucose levels on vascular function can include decreased proliferation of endothelial cells, the impairment of some parameters of vascular responsiveness, and increased endothelial programmed cell death [1921]. It is well established that aggressive blood glucose 
lowering significantly decreases the incidence and severity of microvascular disease including retinopathy, renal failure and peripheral nerve dysfunction $[14,15]$. Recent evidence suggests that increased glycemic control also correlates with a reduction in macrovascular disease; however, the relationship between glucose lowering and a decrease in CVD has been much more difficult to demonstrate [15]. Several explanations have been put forth to rationalize the inability of clinical trials to demonstrate a strong improvement in cardiovascular outcomes through glycemic control including the possibilities that the trials were underpowered, were too short in duration, or were too focused upon fasting glucose rather than postprandial glucose levels. Alternatively, these findings may indicate that the quality of glycemic control presently achievable is insufficient to be effective in protecting against macrovascular disease. Therefore, even short-term deviations in the control of blood glucose may promote vascular dysfunction.

The pathophysiology of T2D-associated CVD is further complicated by multiple risk factors, collectively known as the metabolic syndrome, that commonly accompany chronic hyperglycemia. The metabolic syndrome is clinically defined as a combination of abdominal obesity, insulin resistance (prediabetes), atherogenic dyslipidemia, and hypertension [22]. The metabolic syndrome is a major cause of morbidity and mortality with cardiovascular disease being the primary clinical outcome [22]. Other complications can include respiratory difficulties, chronic skeletal muscle problems, gall bladder disease, infertility, hepatic steatosis, circulatory problems, and certain cancers $[23,24]$.

Therefore, while a role for hyperglycemia in the development and progression of atherosclerosis is supported by a great deal of basic research, the clinical role of elevated glucose levels in macrovascular disease is less clear. Furthermore, despite a great deal of research, the mechanisms that may link high glucose concentrations to the molecular and cellular pathways of disease development are not fully understood. This paper will focus on potential direct proatherogenic consequences of hyperglycemia.

\section{Mechanisms and Pathways Linking Diabetes and Hyperglycemia to CVD and Accelerated Atherosclerosis}

Several mechanisms have been proposed to explain the proatherogenic effects of diabetes and hyperglycemia. In general these have focused upon the intracellular effects of elevated levels of glucose, and the increased availability of glucose metabolites, in cells of the vascular wall. There is evidence that hyperglycemia is associated with increased aldose reductase activity that can lead to increased consumption of NADPH and depletion of GSH levels resulting in elevated levels of reactive oxygen species (ROS) and subsequent cellular damage $[25,26]$. Glucose-induced PKC activation has been implicated in decreased endothelial vasodilation [27] and increased production of ROS [28] that could contribute to endothelial dysfunction. It has also been proposed that the conversion of sorbitol to 3-deoxyglucosone can feed into the production of advanced glycation endproducts (AGEs). AGES are formed through a nonenzymatic process, known as the Maillard reaction, involving the reaction of the aldehyde groups of reducing sugars with the amino groups of proteins $[29,30]$. There are several potential pathways where AGE-modified proteins could be damaging; the formation of AGEs may alter protein function [31], disrupt the extracellular matrix $[31,32]$, and/or lead to the modification of lipoprotein particles thereby increasing their atherogenicity. However the predominant vascular effect of AGEs appears to occur through their interaction with RAGE (receptor for AGE) found on macrophages and endothelial and smooth muscle cells [33-35]. The AGERAGE interaction triggers a signal transduction cascade that results in the production of intracellular ROS that can initiate an inflammatory response [36, 37].

While preclinical evidence supports a causative role for oxidative stress in atherogenesis [38-41], virtually every wellcontrolled clinical trial has failed to show a cardiovascular benefit in diabetic patients receiving antioxidant supplements [42-46]. There are several ways to rationalize this apparent paradox by questioning: the specific antioxidants tested, the doses prescribed, and/or the power and duration of the trials themselves. However, these clinical observations may be indicative of the existence of other important molecular mechanisms or pathways that play a causative role in diabetic atherogenesis in addition to oxidative stress.

2.1. The Hexosamine Pathway. Conditions of hyperglycemia also result in the shunting of excess intracellular glucose through the hexosamine biosynthetic pathway (HBP). In a typical cell, under normoglycemic conditions, 1 to $3 \%$ of total glucose will be converted to glucosamine- 6 phosphate by the enzyme glutamine:fructose- 6 phosphate amidotransferase (GFAT) [47]. When intracellular glucose levels rise, flux through this pathway increases. Furthermore, increased GFAT expression and activity have been reported in tissues from humans with diabetes [48]. The net result is an elevated intracellular concentration of glucosamine. This effect has been observed in cultured cells challenged with elevated concentrations of glucose as well as in vascular and hepatic tissues of hyperglycemic animals [49-52].

Increased hexosamine pathway flux has been implicated in several diabetes-associated complications including insulin resistance $[47,53]$ and pancreatic $\beta$ cell death $[54]$, as well as atherosclerosis [55]. The molecule mechanisms that underlie the pathogenic effects of increased HBP flux are not fully understood. Most research has focused upon the role of UDP-N-acetylglucosamine (UDP-GlcNAc), the endproduct of the HBP pathway and a substrate for both $\mathrm{O}$ - and $\mathrm{N}$-linked protein glycation, as a causative agent. It is well established that elevated glucosamine concentrations drive the O-linked glycosylation of proteins including transcription factors [56] and nuclear pore proteins [57], as well as signaling factors [58] which potentially alters their function, stability, and/or activity. Specifically, studies have suggested that O-glycosylation may regulate transcription, plasma lipids, and gluconeogenesis by modulating the activation 
of RNA polymerase II [59], angiopoietin-like protein 3 [60], FoxO1, and CRTC2 [61, 62], respectively (further reviewed in [63]). Glucosamine has been shown to desensitize insulin-stimulated glucose uptake in both adipocytes [47] and skeletal muscle cells [64], probably by inhibiting the translocation of the glucose transporter, GLUT4, to the cell surface [65]. In addition, increased hexosamine pathway activity can promote the transcription of proinflammatory and prothrombotic factors including TGF- $\alpha$, TGF- $\beta$, and PAI-1 [66-68]. Therefore, the hyperglycemia-induced OGlcNAc modification of proteins may change gene expression patterns and alter the function of specific factors that contribute to a proatherogenic, prothrombophilic vascular environment. More studies are required to test this theory and to precisely determine the factors and downstream pathways that may be involved in the acceleration of vascular disease.

UDP-GlcNAc is also a substrate for $\mathrm{N}$-linked protein glycation that occurs in the endoplasmic reticulum (ER). Nglycosylation is an important posttranslational modification of nascent proteins that is critical for proper protein folding [69]. Mutations in asparagine residues of specific proteins, which are critical for $\mathrm{N}$-glycosylation, result in disrupted folding, secretion and/or activity [70-72]. Tunicamycin, a UDP-GlcNAc antagonist, has been shown to inhibit Nglycosylation and activate the cell's quality control mechanism: the unfolded protein response [73-75]. Ultimately, disruptions in the N-glycation process can lead to an accumulation of unfolded/misfolded proteins in the ER that perturb the ER homeostatic balance; this is known as "ER stress." An additional intracellular effect of glucosamine, which has not been investigated in the context of diabetes and atherosclerosis, is its ability to promote the accumulation of unfolded proteins in the ER, thereby leading to ER dysfunction and cell injury [75-78].

\section{The Endoplasmic Reticulum and the Unfolded Protein Response}

In a typical eukaryotic cell, the ER is responsible for the proper modifying, folding, and trafficking of approximately one-third of all proteins. ER-localized modifications of nascent proteins include disulfide bond formation and $\mathrm{N}$ linked glycosylation, which are critical to protein folding [69]. Unfolded/misfolded proteins are directed to undergo ER-associated degradation (ERAD), and, under physiological conditions, the ER is able to maintain a homeostatic balance between folded and misfolded proteins [79]. When the ER processing capacity is overwhelmed, unfolded/misfolded proteins accumulate and disrupt the ER homeostatic balance; this is known as ER stress.

Traditional ER-stress-inducing agents are known to disrupt protein folding by interfering with disulphide bond formation (dithiothreitol) [80], $\mathrm{ER} \mathrm{Ca}^{2+}$ balance (A23187, thapsigargin) [81], ER membrane structure (palmitate, unesterified cholesterol) $[82,83]$ or by blocking protein $\mathrm{N}$ glycosylation (tunicamycin) [84]. Conditions of ER stress activate the unfolded protein response (UPR) which func- tions to restore ER homeostasis (Figure 1). The UPR is a three pronged signaling cascade that is initiated by transmembrane ER proteins known as inositol-requiring enzyme (IRE)-1, activating transcription factor (ATF)-6, and PKRlike ER kinase (PERK) [85]. Initiation of these pathways alleviates ER stress by decreasing protein synthesis, increasing ER chaperone levels, and facilitating degradation of irreversibly misfolded proteins. Under conditions of chronic ER stress, upregulation of pathways involved in lipid accumulation (SREBP) and inflammation (NF- $\kappa \mathrm{B})$ can occur $[49,86-88]$. If the UPR is unable to restore ER homeostasis, proapoptotic signaling factors (i.e., GADD153/CHOP) are upregulated to initiate programmed cell death [89].

3.1. ER Stress and Atherogenesis. There is increasing experimental evidence in support of a direct and causative role for ER stress in the development and/or progression of atherosclerosis. First, several independent risk factors for CVD, including hyperglycemia [49], hyperhomocysteinemia $[7,88]$, obesity [90], and elevated levels of palmitate [91] and unesterified cholesterol [92], have been associated with ER stress, suggesting that this pathway may represent a common or unifying mechanism of accelerated atherogenesis $[93,94]$. Secondly, activation of the UPR has been noted at all stages of atherosclerotic development, from a fatty streak to an advanced occlusive plaque [95]. Third, conditions of ER stress can activate/dysregulate metabolic pathways that are directly involved in the development of atherosclerotic lesions. ER-stress-inducing agents promote lipid accumulation by activating the sterol regulatory element binding proteins (SREBPs), which are transcription factors that control lipid biosynthesis and uptake $[88,96$, 97]. ER-stress-inducing agents also activate NF- $\kappa \mathrm{B}$, the transcription factor responsible for promoting inflammatory gene expression $[98,99]$. Finally, ER stress has been shown to activate caspases and promote apoptosis of human aortic endothelial cells and other cell types [100, 101]. Together, lipid accumulation, inflammation, and endothelial apoptosis are the hallmark features of atherosclerosis $[102,103]$.

3.2. Glucosamine-Induced ER Stress. Our lab has recently overexpressed the HBP rate limiting enzyme, GFAT, using an adenoviral expression system in cell culture and measured a significant increase in UPR gene expression and downstream effects of ER stress including lipid accumulation, inflammatory gene expression, and apoptotic signaling under hyperglycemic conditions [86]. We have shown that addition of exogenous glucosamine, or increased endogenous production of glucosamine, can disrupt the capacity of the ER to process nascent proteins and initiate an ER stress response. Furthermore, this effect has been observed in cell types that are relevant to the development of atherosclerosis, including human aortic smooth muscle cells, monocyte-derived macrophages, and HepG2 cells $[49,50,100,101]$. Thus, elevated levels of glucosamine may play an important role in ER and cellular dysfunction associated with atherogenesis.

It is not known how increased concentrations of glucosamine (but not mannose) disrupt protein folding in 


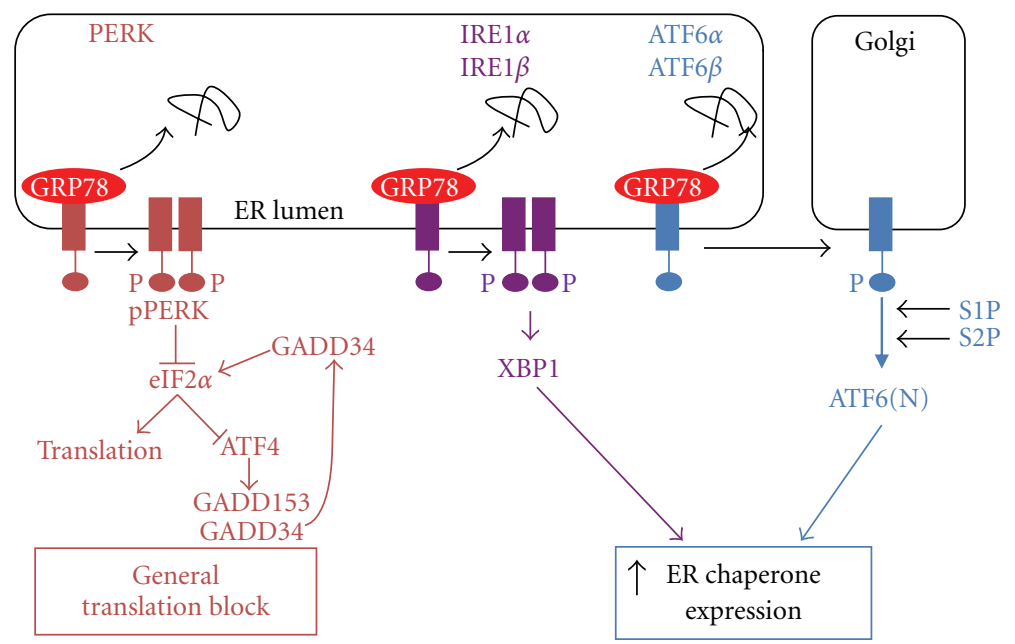

FIGURE 1: The unfolded protein response to endoplasmic reticulum stress. ER stress occurs when the capacity of the ER to process/fold proteins is exceeded by the load of nascent proteins entering the ER. The function of the UPR is to reestablish ER homeostasis by decreasing protein flux into the ER (translation block) while increasing the folding capacity of the ER (increased chaperone expression). Conditions of ER stress lead to the dissociation of ER chaperone GRP78 from the trans-ER-membrane signaling factors PERK, IRE1, and ATF6, resulting in their activation. Activated PERK phosphorylates and inhibits the activity of eIF $2 \alpha$, an essential factor in general protein translation. PERK is also involved with the downstream activation of transcription factors including ATF4 and GADD153. Activated IRE1 assists in the alternative splicing of XBP-1 resulting in the translation of a transcription factor, XBP-1, which is involved in upregulation of the expression of ER chaperones. Activated ATF6 translocates to the Golgi where proteases S1P and S2P release an N-terminal transcription activation domain that works in concert with XBP-1 to upregulate ER chaperone expression.

the ER. UDP-N-acetylglucosamine is an essential substrate for both $\mathrm{O}$ - and $\mathrm{N}$-linked protein glycosylation, and protein glycosylation is an important step in the proper folding of many proteins [69]. It is known that elevated concentrations of glucosamine increase levels of O-linked protein glycosylation [49] and alter N-linked glycosylation patterns of specific proteins including ApoB100 [104]. It is possible that either of these effects could promote ER stress. In cultured HepG2 cells, our lab has shown that PUGNAc, an inhibitor of OGlcNAcase, increases protein-O-GlcNAc levels but does not promote ER stress [49]. This may suggest that glucosamineinduced ER stress is caused by free and not protein $\mathrm{O}$ linked glucosamine. We hypothesize that increased levels of glucosamine, or a derivative of glucosamine, may interfere with a step in the $\mathrm{N}$-linked glycation of proteins resulting in the production of misfolded proteins and the activation of the UPR.

Elevated levels of glucosamine and glucosamine-induced ER stress have been previously implicated in acquired insulin resistance $[47,53,105,106]$; however, there is some controversy to whether this effect is physiologically relevant in humans. Incubation of relatively high concentrations of glucosamine $(1-10 \mathrm{mmol} / \mathrm{L})$ in adipose, muscle, or endothelial cell cultures has been implicated in impaired insulin action [106-109]. Furthermore, high levels of intravenously injected glucosamine (plasma concentrations of $0.5-1.8 \mathrm{mmol} / \mathrm{L}$ ) in both animals and humans have also been shown to cause insulin resistance $[110,111]$. The recommended daily dose of oral glucosamine supplements, commonly taken to treat joint pain, are far lower (plasma concentrations of $\sim 3 \mu \mathrm{mol} / \mathrm{L}$ ), and data suggest that these supplements have no effect on insulin sensitivity $[112,113]$.
Additional studies will be required to determine the effects of chronic hyperglycemia on endogenous, intracellular levels of glucosamine and possible effects on insulin resistance.

\section{Hyperglycemia, ER Stress, and Accelerated Atherosclerosis}

To investigate the molecular mechanisms that link hyperglycemia to atherosclerosis, we have established a model in which we inject $\mathrm{ApoE}^{-/-}$mice with multiple low doses of streptozotocin (STZ) [49, 50, 114]. Using this model we have observed a correlation between hyperglycemia, the accumulation of glucosamine in the artery wall, vascular ER stress, and accelerated atherogenesis [49] (Figure 2). Significantly, ER stress levels in the endothelium of hyperglycemic mice increase prior to the development of the atherosclerotic lesions, a result that is consistent with ER stress playing a causative role in lesion development [50]. In addition, accelerated lesion development is observed in these diabetic mice before the onset of dyslipidemia, suggesting that hyperglycemia is sufficient to independently promote the activation of proatherogenic processes [49].

In a direct test of the atherogenic potential of glucosamine, we have recently found that $\mathrm{ApoE}^{-/-}$mice given drinking water containing $5 \%$ glucosamine $(\mathrm{w} / \mathrm{v})$ for 7 weeks have significantly increased vascular and hepatic ER stress levels in addition to larger atherosclerotic lesions than mice given regular water or water containing $5 \%$ mannitol $(\mathrm{w} / \mathrm{v})$ [115]. This is consistent with a report from Tannock et al. who found that 5 weeks of glucosamine supplementation increased lesion size in LDL-receptor-deficient mice [116]. 

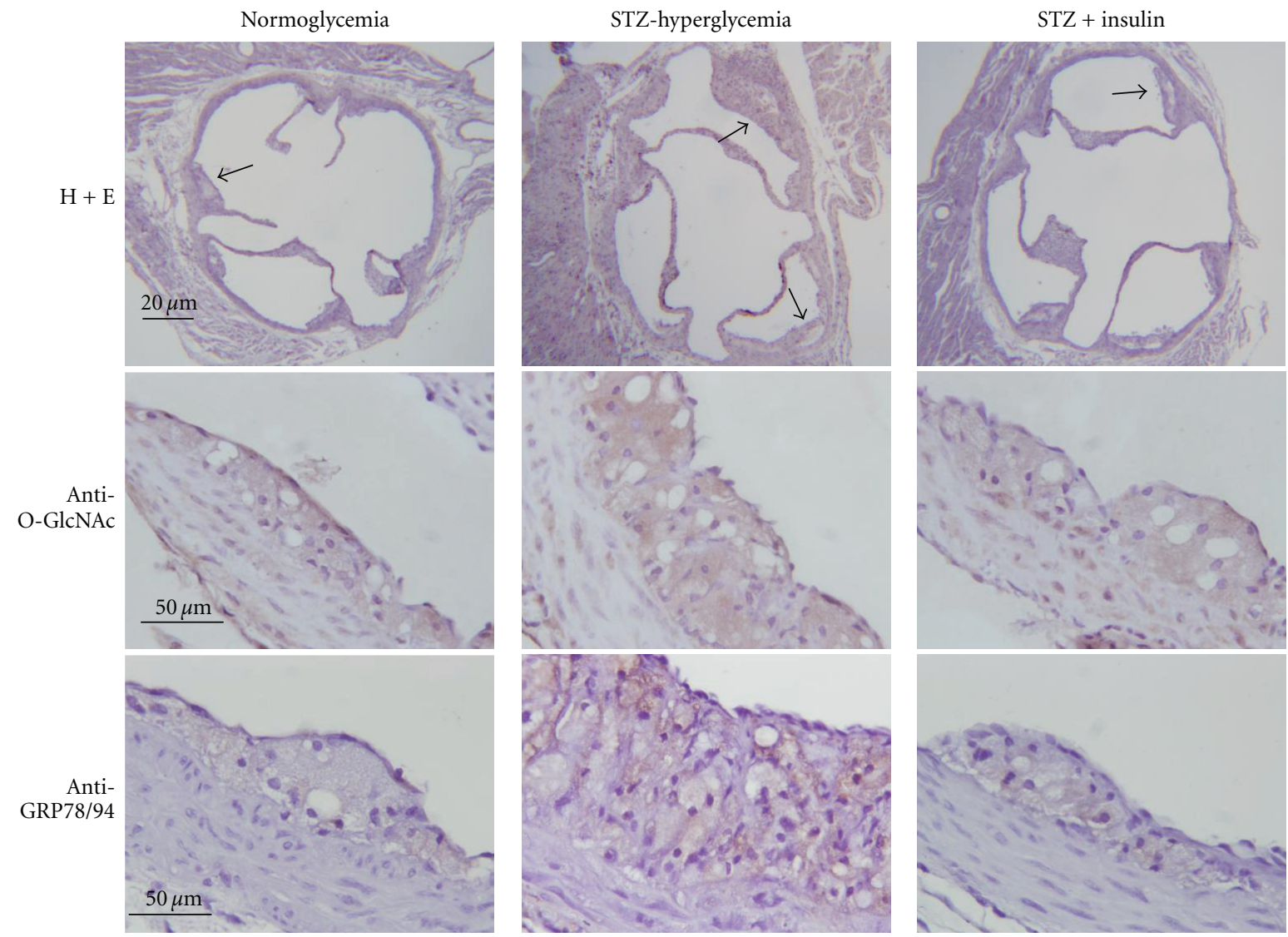

FIGURe 2: Analysis of aortic root from normoglycemic, STZ-injected hyperglycemic, and STZ-injected insulin-treated ApoE ${ }^{-/-}$mice. Hyperglycemic mice show increased vascular O-linked GlcNAc, elevated levels of ER stress markers (GRP78/94), and significantly accelerated atherosclerotic lesion development, relative to normoglycemic controls. Normalization of glucose levels with insulin attenuates O-GlcNAc accumulation, ER stress, and atherogenesis.

Our data suggests that glucosamine-induced ER stress plays a direct and causative role in accelerated atherogenesis.

\section{ER Stress in Patients with Metabolic Syndrome}

There is ample evidence in vitro and in animal models to support a role for ER stress in the development and complications of diabetes. Recently, small clinically relevant studies involving humans with metabolic syndrome have been carried out. Patients with diabetic nephropathy have been shown to have increased GFAT expression in glomerular epithelial and mesangial cells and that GFAT is expressed in most tissues involved in diabetic complications [48, 117]. Pancreatic beta cells isolated from type 2 diabetics have been shown to have marked expression of ER stress markers [118] and increased susceptibility to ER stress compared to nondiabetic controls [119] and that ER stress may contribute to IL- $1 \beta$ production, mild islet inflammation [120], and $\beta$ cell failure [118]. Our lab has recently shown that isolated leukocytes from human subjects with metabolic syndrome, compared to healthy subjects, have elevated levels of ER stress markers and that there is an association between acute and chronic dysglycemia and ER stress in humans [86].
Each of these trials is consistent with diabetes-associated ER stress playing a clinically relevant role in the pathogenesis of diabetic complications.

\section{Targets for Potential Therapeutic Intervention}

The identification of a role for ER stress and/or the UPR in the development and progression of diabetes-associated atherosclerosis is significant, not only because it gives us insight on an important disease process, but also because it illuminates novel potential targets for therapeutic intervention (Figure 3). Efforts to develop strategies to manipulate the UPR have already begun, especially with respect to other diseases and disorders in which ER stress is thought to play a role. At least three general approaches have been used to address this problem. The first involves reducing the levels of ER stress directly by relieving the load of misfolded proteins though the addition of chemical chaperones such as 4phenylbutyric acid (4-PBA), taurine-conjugated ursodeoxycholic acid (TUDCA), or dimethyl sulfoxide (DMSO) [121123]. The mechanisms by which these small molecules function to reduce ER stress levels are not well defined. However, such strategies have been shown to be effective 


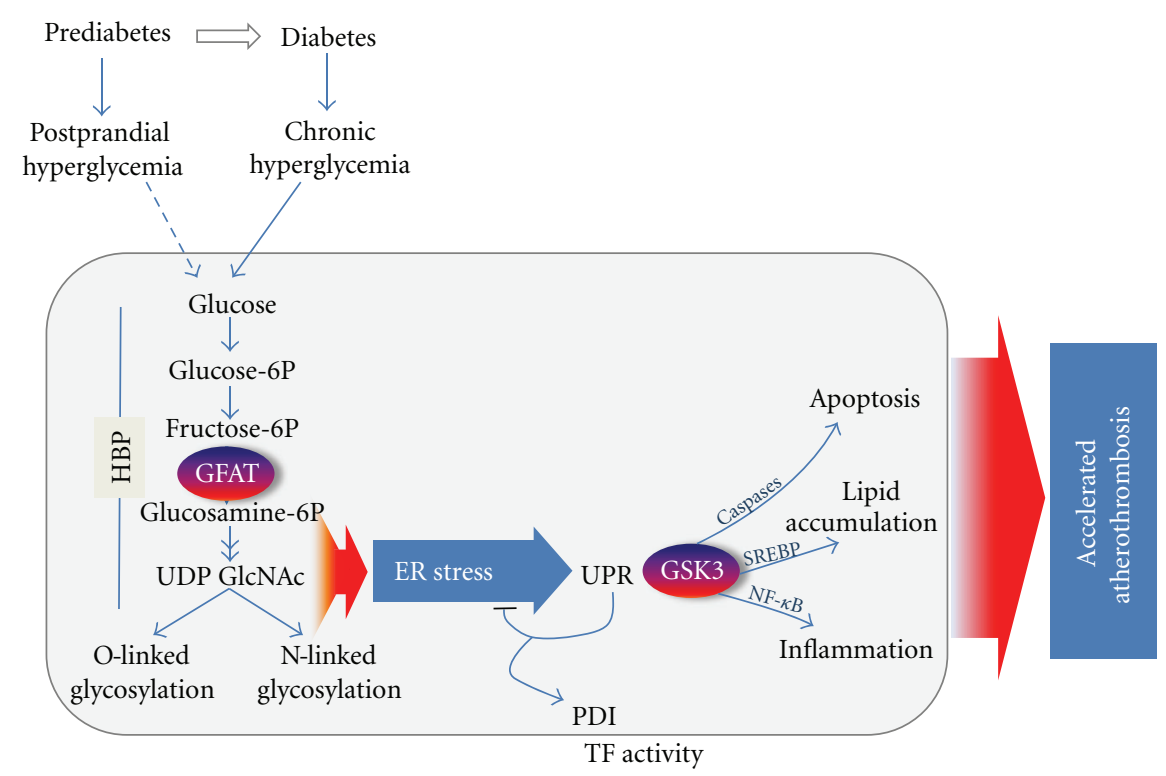

FIGURE 3: Working model of diabetes-associated accelerated atherothrombosis. Chronic hyperglycemia leads to increased flux through the hexosamine biosynthesis pathway (HBP) resulting in accumulation of UDP-N-acetylglucosamine (UDP-GlcNAc), a substrate for both Oand N-linked protein glycosylation, as well as increased levels of ER stress. Disruptions in ER homeostasis lead to activation of the unfolded protein response (UPR) and downstream effects including activation of glycogen synthase kinase (GSK)-3. Our results suggest that ERstress-induced GSK-3 induces proatherogenic processes leading to the accelerated development of atherothrombosis.

in vitro and in vivo, and 4-phenylbutyric acid has been shown to attenuate atherosclerosis in an $\mathrm{ApoE}^{-1-}$ mouse model [124]. A second strategy is to augment the protective aspects of the endogenous UPR. This has previously been accomplished through the over-expression of ER-resident protein chaperones including GRP78. The third approach is to target some of the detrimental downstream effects of ER stress. Examples of this strategy include the use of salubrinal which inhibits the phosphatase GADD34 from reactivating eIF2 $\alpha$, thereby maintaining the PERK pathway-induced translation block (Figure 1). Other possible targets for intervention would include proinflammatory and/or proapoptotic factors such as ASK1, p38MAPK, or GADD153/CHOP. Indeed, GADD153/CHOP-deficient mice are resistant to accelerated atherosclerosis $[125,126]$. Recently we have identified glutamine:fructose-6-phosphate amidotransferase (GFAT) and glycogen synthase kinase (GSK)-3 as two enzymes involved in ER stress and potential targets for therapeutic intervention.

\subsection{Glutamine:Fructose-6-phosphate Amidotransferase} (GFAT). The potential role of glucosamine-induced ER stress in diabetic atherogenesis highlights the importance of glutamine:fructose-6-phosphate amidotransferase (GFAT), the rate-limiting enzyme in the conversion of glucose to glucosamine, also known as the hexosamine pathway $[127,128]$. A central role for GFAT activity in the ER stress pathway is supported by our finding that inhibition of GFAT attenuates glucose-induced ER stress [49] and that overexpression of GFAT is sufficient to promote ER stress in HepG2 cells cultured in normoglycemic conditions [86]. We are currently developing strategies to modulate GFAT activity in vitro and in our mouse models. These tools will be used to investigate the potential effects of regulating GFAT activity on the UPR and on activation of proatherogenic processes.

6.2. Glycogen Synthase Kinase (GSK)-3. The mechanisms that link conditions of ER stress to the activation of proatherogenic pathways are not known. GSK- $3 \alpha$ and $\beta$ are two homologous serine/threonine kinases that are involved in a diverse number of intracellular signaling pathways [129]. We have shown using small molecule inhibitors and GSK$3 \alpha^{-/-}$and GSK- $3 \beta^{-1-}$ mouse embryonic fibroblasts that GSK-3-deficiency attenuates ER-stress-induced apoptosis and lipid accumulation [114, 130-132]. In vivo we have shown that hyperglycemic mice fed a diet supplemented with valproate, a compound that inhibits GSK-3 activity, have reduced hepatic GSK-3 activity and reduced lesion volume at the aortic sinus [114]. Together, the above findings support our hypothesis that glucosamine-induced ER stress plays a role in accelerated atherogenesis and identifies GSK-3 as a potential target for antiatherogenic therapy. The limitation of targeting GSK-3 arises from the central role that this kinase plays in many diverse metabolic processes and the possibility of detrimental side-effects of small molecular inhibitors [118].

\section{Conclusions}

Because of the cardiovascular risks of diabetes and the increasing prevalence of type 2 diabetes, it is essential that we further our knowledge of how and why diabetes mellitus and hyperglycemia promote cardiovascular disease. 
Currently, and for the near future, the primary strategy for managing cardiovascular disease in the diabetic population will be through the control of hyperglycemia and through the treatment of associated complications such as hypertension and dyslipidemia using established medications such as ACE inhibitors, statins, and fibrates.

The continued identification and investigation of pathways linking hyperglycemia and diabetes mellitus to atherosclerosis is important to the development of new and effective antiatherosclerotic therapies that are tailored to individuals with diabetes. A great deal of research has been focused upon the role of hyperglycemia in the development and progression of atherosclerosis in cell culture and animal model systems. Several mechanisms have been identified that appear to link glucose to proatherogenic processes. The most promising of these, the polyol pathway, PKC activation, the hexosamine pathway, and the AGE-RAGE interaction, show potential and are actively being evaluated as targets for putative antiatherogenic therapies. Thus far, however, all interventions targeting the effects of hyperglycemia, including direct glucose lowering, appear to show greater effect in the treatment of microvascular complications than in the control of macrovascular disease. This is likely due, at least in part, to the complexities of atherosclerosis and current limitations of the animal models available to researchers who study the development and progression of atherosclerosis. Additional studies are obviously required to further our understanding of this important disease.

\section{References}

[1] P. S. Yusuf, S. Hawken, S. Ôunuu et al., "Effect of potentially modifiable risk factors associated with myocardial infarction in 52 countries (the INTERHEART study): case-control study," The Lancet, vol. 364, no. 9438, pp. 937-952, 2004.

[2] S. Yusuf, S. Reddy, S. Ônpuu, and S. Anand, "Global burden of cardiovascular diseases. Part I: general considerations, the epidemiologic transition, risk factors, and impact of urbanization," Circulation, vol. 104, no. 22, pp. 2746-2753, 2001.

[3] G. Danaei, M. M. Finucane, Y. Lu et al., "National, regional, and global trends in fasting plasma glucose and diabetes prevalence since 1980: systematic analysis of health examination surveys and epidemiological studies with 370 countryyears and 2.7 million participants," The Lancet, vol. 378, no. 9785, pp. 31-40, 2011.

[4] P. Hossain, B. Kawar, and M. El Nahas, "Obesity and diabetes in the developing world-a growing challenge," The New England Journal of Medicine, vol. 356, no. 3, pp. 213-215, 2007.

[5] S. M. Haffner, S. Lehto, T. Ronnemaa, K. Pyorala, and M. Laakso, "Mortality from coronary heart disease in subjects with type 2 diabetes and in nondiabetic subjects with and without prior myocardial infarction," The New England Journal of Medicine, vol. 339, no. 4, pp. 229-234, 1998.

[6] H. C. Gerstein, K. Malmberg, S. Capes, and S. Yusuf, "Cardiovascular diseases," in Evidence-Based Diabetes Care, H. C. Gerstein and R. B. Haynes, Eds., pp. 488-514, BC Decker, Ontario, Canada, 2001.

[7] S. Lehto, T. Ronnemaa, K. Pyorala, and M. Laakso, "Cardiovascular risk factors clustering with endogenous hyperinsu- linemia predict death from coronary heart disease in patients with Type II diabetes," Diabetologia, vol. 43, no. 2, pp. 148$155,2000$.

[8] R. J. W. Middelbeek and E. S. Horton, "The role of glucose as an independent cardiovascular risk factor," Current Diabetes Reports, vol. 7, no. 1, pp. 43-49, 2007.

[9] E. Selvin, J. Coresh, S. H. Golden, F. L. Brancati, A. R. Folsom, and M. W. Steffes, "Glycemic control and coronary heart disease risk in persons with and without diabetes: the atherosclerosis risk in communities study," Archives of Internal Medicine, vol. 165, no. 16, pp. 1910-1916, 2005.

[10] H. C. Gerstein, M. E. Miller, R. P. Byington et al., "Effects of intensive glucose lowering in type 2 diabetes," The New England Journal of Medicine, vol. 358, no. 24, pp. 2545-2559, 2008.

[11] A. Patel, S. MacMahon, J. Chalmers et al., "Intensive blood glucose control and vascular outcomes in patients with type 2 diabetes," The New England Journal of Medicine, vol. 358, no. 24, pp. 2560-2572, 2008.

[12] R. R. Holman, S. K. Paul, M. A. Bethel, H. A. W. Neil, and D. R. Matthews, "Long-term follow-up after tight control of blood pressure in type 2 diabetes," The New England Journal of Medicine, vol. 359, no. 15, pp. 1565-1576, 2008.

[13] W. Duckworth, C. Abraira, T. Moritz et al., "Glucose control and vascular complications in veterans with type 2 diabetes," The New England Journal of Medicine, vol. 360, no. 2, pp. 129139, 2009.

[14] D. M. Nathan, J. Lachin, P. Cleary et al., "Intensive diabetes therapy and carotid intima-media thickness in type 1 diabetes mellitus," The New England Journal of Medicine, vol. 348, no. 23, pp. 2294-2303, 2003.

[15] R. Turner, "Intensive blood-glucose control with sulphonylureas or insulin compared with conventional treatment and risk of complications in patients with type 2 diabetes (UKPDS 33)," The Lancet, vol. 352, no. 9131, pp. 837-853, 1998.

[16] S. M. Haffner, "The importance of hyperglycemia in the nonfasting state to the development of cardiovascular disease," Endocrine Reviews, vol. 19, no. 5, pp. 583-592, 1998.

[17] E. Standl, B. Balletshofer, B. Dahl et al., "Predictors of 10-year macrovascular and overall mortality in patients with NIDDM: the Munich General Practitioner Project," Diabetologia, vol. 39, no. 12, pp. 1540-1545, 1996.

[18] S. Lehto, T. Ronnemaa, S. M. Haffner, K. Pyorala, V. Kallio, and M. Laakso, "Dyslipidemia and hyperglycemia predict coronary heart disease events in middle-aged patients with NIDDM," Diabetes, vol. 46, no. 8, pp. 1354-1359, 1997.

[19] S. M. Santilli, V. D. Fiegel, D. E. Aldridge, and D. R. Knighton, "The effect of diabetes on the proliferation of aortic endothelial cells," Annals of Vascular Surgery, vol. 6, no. 6, pp. 503-510, 1992.

[20] F. C. Huvers, P. W. De Leeuw, A. J. H. M. Houben et al., "Endothelium-dependent vasodilatation, plasma markers of endothelial function, and adrenergic vasoconstrictor responses in type 1 diabetes under near-normoglycemic conditions," Diabetes, vol. 48, no. 6, pp. 1300-1307, 2000.

[21] L. Quagliaro, L. Piconi, R. Assaloni, L. Martinelli, E. Motz, and A. Ceriello, "Intermittent high glucose enhances apoptosis related to oxidative stress in human umbilical vein endothelial cells: the role of protein kinase $\mathrm{C}$ and $\mathrm{NAD}(\mathrm{P}) \mathrm{H}-$ oxidase activation," Diabetes, vol. 52, no. 11, pp. 2795-2804, 2003.

[22] S. M. Grundy, H. B. Brewer, J. I. Cleeman, S. C. Smith Jr., and C. Lenfant, "Definition of metabolic syndrome: report 
of the National Heart, Lung, and Blood Institute/American Heart Association conference on scientific issues related to definition," Circulation, vol. 109, no. 3, pp. 433-438, 2004.

[23] World Health Organization, "Obesity: preventing and managing the global epidemic," WHO Technical Report Series, no. 894, 2003.

[24] S. M. Grundy, "Metabolic complications of obesity," Endocrine, vol. 13, no. 2, pp. 155-165, 2000.

[25] A. Y. W. Lee and S. S. M. Chung, "Contributions of polyol pathway to oxidative stress in diabetic cataract," The FASEB Journal, vol. 13, no. 1, pp. 23-30, 1999.

[26] C. A. Gleissner, J. M. Sanders, J. Nadler, and K. Ley, "Upregulation of aldose reductase during foam cell formation as possible link among diabetes, hyperlipidemia, and atherosclerosis," Arteriosclerosis, Thrombosis, and Vascular Biology, vol. 28, no. 6, pp. 1137-1143, 2008.

[27] B. Tesfamariam, M. L. Brown, and R. A. Cohen, "Elevated glucose impairs endothelium-dependent relaxation by activating protein kinase C," The Journal of Clinical Investigation, vol. 87, no. 5, pp. 1643-1648, 1991.

[28] T. Inoguchi, P. Li, F. Umeda et al., "High glucose level and free fatty acid stimulate reactive oxygen species production through protein kinase C-dependent activation of $\mathrm{NAD}(\mathrm{P}) \mathrm{H}$ oxidase in cultured vascular cells," Diabetes, vol. 49, no. 11, pp. 1939-1945, 2000.

[29] K. J. Wells-Knecht, D. V. Zyzak, J. E. Litchfield, S. R. Thorpe, and J. W. Baynes, "Mechanism of autoxidative glycosylation: identification of glyoxal and arabinose as intermediates in the autoxidative modification of proteins by glucose," Biochemistry, vol. 34, no. 11, pp. 3702-3709, 1995.

[30] T. P. Degenhardt, S. R. Thorpe, and J. W. Baynes, "Chemical modification of proteins by methylglyoxal," Cellular and Molecular Biology, vol. 44, no. 7, pp. 1139-1145, 1998.

[31] J. Liu, M. R. Masurekar, D. E. Vatner et al., "Glycation endproduct cross-link breaker reduces collagen and improves cardiac function in aging diabetic heart," American Journal of Physiology, vol. 285, no. 6, pp. H2587-H2591, 2003.

[32] S. Tanaka, G. Avigad, B. Brodsky, and E. F. Eikenberry, "Glycation induces expansion of the molecular packing of collagen," Journal of Molecular Biology, vol. 203, no. 2, pp. 495-505, 1988.

[33] M. Neeper, A. M. Schmidt, J. Brett et al., "Cloning and expression of a cell surface receptor for advanced glycosylation end products of proteins," The Journal of Biological Chemistry, vol. 267, no. 21, pp. 14998-15004, 1992.

[34] Y. M. Li, T. Mitsuhashi, D. Wojciechowicz et al., "Molecular identity and cellular distribution of advanced glycation endproduct receptors: relationship of p60 to OST-48 and p90 to $80 \mathrm{~K}-\mathrm{H}$ membrane proteins," Proceedings of the National Academy of Sciences of the United States of America, vol. 93, no. 20, pp. 11047-11052, 1996.

[35] B. Smedsrod, J. Melkko, N. Araki, H. Sano, and S. Horiuchi, "Advanced glycation end products are eliminated by scavenger-receptor-mediated endocytosis in hepatic sinusoidal Kupffer and endothelial cells," Biochemical Journal, vol. 322, part 2, pp. 567-573, 1997.

[36] M. A. Hofmann, E. Lalla, Y. Lu et al., "Hyperhomocysteinemia enhances vascular inflammation and accelerates atherosclerosis in a murine model," The Journal of Clinical Investigation, vol. 107, no. 6, pp. 675-683, 2001.

[37] M. Brownlee, "The pathobiology of diabetic complications: a unifying mechanism," Diabetes, vol. 54, no. 6, pp. 1615-1625, 2005.
[38] S. V. Brodsky, O. Gealekman, J. Chen et al., "Prevention and reversal of premature endothelial cell senescence and vasculopathy in obesity-induced diabetes by ebselen," Circulation Research, vol. 94, no. 3, pp. 377-384, 2004.

[39] A. M. Schmidt, O. Hori, Jing Xian Chen et al., "Advanced glycation endproducts interacting with their endothelial receptor induce expression of vascular cell adhesion molecule-1 (VCAM-1) in cultured human endothelial cells and in mice: a potential mechanism for the accelerated vasculopathy of diabetes," The Journal of Clinical Investigation, vol. 96, no. 3, pp. 1395-1403, 1995.

[40] L. G. Bucciarelli, T. Wendt, W. Qu et al., "RAGE blockade stabilizes established atherosclerosis in diabetic apolipoprotein E-null mice," Circulation, vol. 106, no. 22, pp. 2827-2835, 2002.

[41] A. Soro-Paavonen, A. M. D. Watson, J. Li et al., "Receptor for advanced glycation end products (RAGE) deficiency attenuates the development of atherosclerosis in diabetes," Diabetes, vol. 57, no. 9, pp. 2461-2469, 2008.

[42] H. C. Gerstein, S. Yusuf, J. F. E. Mann et al., "Effects of ramipril on cardiovascular and microvascular outcomes in people with diabetes mellitus: results of the HOPE study and MICRO-HOPE substudy," The Lancet, vol. 355, no. 9200, pp. 253-259, 2000

[43] E. M. Lonn, S. Yusuf, V. Dzavik et al., "Effects of Ramipril and vitamin E on atherosclerosis: the Study to Evaluate Carotid Ultrasound changes in patients treated with Ramipril and vitamin E (SECURE)," Circulation, vol. 103, no. 7, pp. 919925, 2001.

[44] B. M. McQuillan, J. Hung, J. P. Beilby, M. Nidorf, and P. L. Thompson, "Antioxidant vitamins and the risk of carotid atherosclerosis: the perth carotid ultrasound disease assessment study (CUDAS)," Journal of the American College of Cardiology, vol. 38, no. 7, pp. 1788-1794, 2001.

[45] E. Lonn, "Effects of long-term vitamin E supplementation on cardiovascular events and cancer: a randomized controlled trial," JAMA, vol. 293, no. 11, pp. 1338-1347, 2005.

[46] M. J. Thomson, V. Puntmann, and J. C. Kaski, "Atherosclerosis and oxidant stress: the end of the road for antioxidant vitamin treatment?" Cardiovascular Drugs and Therapy, vol. 21, no. 3, pp. 195-210, 2007.

[47] S. Marshall, V. Bacote, and R. R. Traxinger, "Discovery of a metabolic pathway mediating glucose-induced desensitization of the glucose transport system: role of hexosamine in the induction of insulin resistance," The Journal of Biological Chemistry, vol. 266, no. 8, pp. 4706-4712, 1991.

[48] A. G. Nerlich, U. Sauer, V. Kolm-Litty, E. Wagner, M. Koch, and E. D. Schleicher, "Expression of glutamine:fructose-6phosphate amidotransferase in human tissues: evidence for high variability and distinct regulation in diabetes," Diabetes, vol. 47 , no. 2, pp. 170-178, 1998.

[49] G. H. Werstuck, M. I. Khan, G. Femia et al., "Glucosamineinduced endoplasmic reticulum dysfunction is associated with accelerated atherosclerosis in a hyperglycemic mouse model," Diabetes, vol. 55, no. 1, pp. 93-101, 2006.

[50] M. I. Khan, B. A. Pichna, Y. Shi, A. J. Bowes, and G. H. Werstuck, "Evidence supporting a role for endoplasmic reticulum stress in the development of atherosclerosis in a hyperglycaemic mouse model," Antioxidants and Redox Signaling, vol. 11, no. 9, pp. 2289-2298, 2009.

[51] N. Fülöp, M. M. Mason, K. Dutta et al., "Impact of Type 2 diabetes and aging on cardiomyocyte function and O-linked $\mathrm{N}$-acetylglucosamine levels in the heart," American Journal of Physiology, vol. 292, no. 4, pp. C1370-C1378, 2007. 
[52] G. Wu, T. E. Haynes, W. Yan, and C. J. Meininger, "Presence of glutamine:fructose-6-phosphate amidotransferase for glucosamine-6-phosphate synthesis in endothelial cells: effects of hyperglycaemia and glutamine," Diabetologia, vol. 44, no. 2, pp. 196-202, 2001.

[53] G. Veerababu, J. Tang, R. T. Hoffman et al., "Overexpression of glutamine:fructose-6-phosphate amidotransferase in the liver of transgenic mice results in enhanced glycogen storage, hyperlipidemia, obesity, and impaired glucose tolerance," Diabetes, vol. 49, no. 12, pp. 2070-2078, 2000.

[54] K. Liu, A. J. Paterson, E. Chin, and J. E. Kudlow, "Glucose stimulates protein modification by O-linked GlcNAc in pancreatic $\beta$ cells: linkage of O-linked GlcNAc to $\beta$ cell death," Proceedings of the National Academy of Sciences of the United States of America, vol. 97, no. 6, pp. 2820-2825, 2000.

[55] S. Stender and P. Astrup, "Glucosamine and experimental atherosclerosis. Increased wet weight and changed composition of cholesterol fatty acids in aorta of rabbits fed a cholesterol enriched diet with added glucosamine," Atherosclerosis, vol. 26, no. 2, pp. 205-213, 1977.

[56] G. Majumdar, A. Harmon, R. Candelaria, A. MartinezHernandez, R. Raghow, and S. S. Solomon, "O-glycosylation of Sp1 and transcriptional regulation of the calmodulin gene by insulin and glucagon," American Journal of Physiology, vol. 285, no. 3, pp. E584-E591, 2003.

[57] I. Han, E. S. Oh, and J. E. Kudlow, "Responsiveness of the state of $\mathrm{O}$-linked $\mathrm{N}$-acetylglucosamine modification of nuclear pore protein p62 to the extracellular glucose concentration," Biochemical Journal, vol. 350, no. 1, pp. 109$114,2000$.

[58] X. L. Du, D. Edelstein, S. Dimmeler, Q. Ju, C. Sui, and M. Brownlee, "Hyperglycemia inhibits endothelial nitric oxide synthase activity by posttranslational modification at the Akt site," The Journal of Clinical Investigation, vol. 108, no. 9, pp. 1341-1348, 2001.

[59] S. P. Jackson and R. Tjian, "O-glycosylation of eukaryotic transcription factors: implications for mechanisms of transcriptional regulation," Cell, vol. 55, no. 1, pp. 125-133, 1988.

[60] K. T. B. G. Schjoldager, M. B. Vester-Christensen, E. P. Bennett et al., "O-glycosylation modulates proprotein convertase activation of angiopoietin-like protein 3: possible role of polypeptide GalNAc-transferase-2 in regulation of concentrations of plasma lipids," The Journal of Biological Chemistry, vol. 285, no. 47, pp. 36293-36303, 2010.

[61] M. Kuo, V. Zilberfarb, N. Gangneux, N. Christeff, and T. Issad, "O-glycosylation of FoxO1 increases its transcriptional activity towards the glucose 6-phosphatase gene," FEBS Letters, vol. 582, no. 5, pp. 829-834, 2008.

[62] R. Dentin, S. Hedrick, J. Xie, J. Yates, and M. Montminy, "Hepatic glucose sensing via the CREB coactivator CRTC2," Science, vol. 319, no. 5868, pp. 1402-1405, 2008.

[63] G. A. Ngoh, H. T. Facundo, A. Zafir, and S. P. Jones, "OGlcNAc signaling in the cardiovascular system," Circulation Research, vol. 107, no. 2, pp. 171-185, 2010.

[64] R. C. Cooksey and D. A. McClain, "Transgenic mice overexpressing the rate-limiting enzyme for hexosamine synthesis in skeletal muscle or adipose tissue exhibit total body insulin resistance," Annals of the New York Academy of Sciences, vol. 967, pp. 102-111, 2002.

[65] A. D. Baron, J. S. Zhu, J. H. Zhu, H. Weldon, L. Maianu, and W. T. Garvey, "Glucosamine induces insulin resistance in vivo by affecting GLUT 4 translocation in skeletal muscle. Implications for glucose toxicity," The Journal of Clinical Investigation, vol. 96, no. 6, pp. 2792-2801, 1995.
[66] V. Kolm-Litty, U. Sauer, A. Nerlich, R. Lehmann, and E. D. Schleicher, "High glucose-induced transforming growth factor $\beta 1$ production is mediated by the hexosamine pathway in porcine glomerular mesangial cells," The Journal of Clinical Investigation, vol. 101, no. 1, pp. 160-169, 1998.

[67] M. C. Daniels, P. Kansal, T. M. Smith, A. J. Paterson, J. E. Kudlow, and D. A. McClain, "Glucose regulation of transforming growth factor- $\alpha$ expression is mediated by products of the hexosamine biosynthesis pathway," Molecular Endocrinology, vol. 7, no. 8, pp. 1041-1048, 1993.

[68] I. Gabriely, X. M. Yang, J. A. Cases, X. H. Ma, L. Rossetti, and N. Barzilai, "Hyperglycemia induces PAI-1 gene expression in adipose tissue by activation of the hexosamine biosynthetic pathway," Atherosclerosis, vol. 160, no. 1, pp. 115-122, 2002.

[69] A. Helenius, "How N-linked oligosaccharides affect glycoprotein folding in the endoplasmic reticulum," Molecular Biology of the Cell, vol. 5, no. 3, pp. 253-265, 1994.

[70] M. Bence and M. Sahin-Tõth, "Asparagine-linked glycosylation of human chymotrypsin $\mathrm{C}$ is required for folding and secretion but not for enzyme activity," The FEBS Journal, vol. 278, no. 22, pp. 4338-4350, 2011.

[71] N. Branza-Nichita, G. Negroiu, A. J. Petrescu et al., "Mutations at critical $\mathrm{N}$-glycosylation sites reduce tyrosinase activity by altering folding and quality control," The Journal of Biological Chemistry, vol. 275, no. 11, pp. 8169-8175, 2000.

[72] P. Wujek, E. Kida, M. Walus, K. E. Wisniewski, and A. A. Golabek, "N-glycosylation is crucial for folding, trafficking, and stability of human tripeptidyl-peptidase I," The Journal of Biological Chemistry, vol. 279, no. 13, pp. 12827-12839, 2004.

[73] H. P. Harding, Y. Zhang, and D. Ron, "Protein translation and folding are coupled by an endoplasmic- reticulum-resident kinase," Nature, vol. 397, no. 6716, pp. 271-274, 1999.

[74] R. J. Kaufman, "Stress signaling from the lumen of the endoplasmic reticulum: coordination of gene transcriptional and translational controls," Genes and Development, vol. 13, no. 10, pp. 1211-1233, 1999.

[75] M. J. Morin, C. W. Porter, P. McKernan, and R. J. Bernacki, "The biochemical and ultrastructural effects of tunicamycin and D-glucosamine in L1210 leukemic cells," Journal of Cellular Physiology, vol. 114, no. 2, pp. 162-172, 1983.

[76] H. Y. Lin, P. Masso-Welch, Y. P. Di, J. W. Cai, J. W. Shen, and J. R. Subjeck, "The $170-\mathrm{kDa}$ glucose-regulated stress protein is an endoplasmic reticulum protein that binds immunoglobulin," Molecular Biology of the Cell, vol. 4, no. 11, pp. 1109-1119, 1993.

[77] D. Miskovic, L. Salter-Cid, N. Ohan, M. Flajnik, and J. J. Heikkila, "Isolation and characterization of a cDNA encoding a Xenopus immunoglobulin binding protein, BiP (Grp78)," Comparative Biochemistry and Physiology, vol. 116, no. 2, pp. 227-234, 1997.

[78] A. S. Lee, "The glucose-regulated proteins: stress induction and clinical applications," Trends in Biochemical Sciences, vol. 26, no. 8, pp. 504-510, 2001.

[79] E. Lai, T. Teodoro, and A. Volchuk, "Endoplasmic reticulum stress: signaling the unfolded protein response," Physiology, vol. 22, no. 3, pp. 193-201, 2007.

[80] E. Jamsa, M. Simonen, and M. Makarow, "Selective retention of secretory proteins in the yeast endoplasmic reticulum by treatment of cells with a reducing agent," Yeast, vol. 10, no. 3, pp. 355-370, 1994.

[81] W. W. Li, S. Alexandre, X. Cao, and A. S. Lee, "Transactivation of the grp78 promoter by $\mathrm{Ca}^{2+}$ depletion. A comparative 
analysis with $\mathrm{A} 23187$ and the endoplasmic reticulum $\mathrm{Ca}^{2+}{ }_{-}$ ATPase inhibitor thapsigargin," The Journal of Biological Chemistry, vol. 268, no. 16, pp. 12003-12009, 1993.

[82] N. M. Borradaile, X. Han, J. D. Harp, S. E. Gale, D. S. Ory, and J. E. Schaffer, "Disruption of endoplasmic reticulum structure and integrity in lipotoxic cell death," Journal of Lipid Research, vol. 47, no. 12, pp. 2726-2737, 2006.

[83] T. DeVries-Seimon, Y. Li, M. Y. Pin et al., "Cholesterolinduced macrophage apoptosis requires ER stress pathways and engagement of the type A scavenger receptor," Journal of Cell Biology, vol. 171, no. 1, pp. 61-73, 2005.

[84] J. Feige and I. E. Scheffler, "Analysis of the protein glycosylation defect of a temperature-sensitive cell cycle mutant by the use of mutant cells overexpressing the human epidermal growth factor receptor after transfection of the gene," Journal of Cellular Physiology, vol. 133, no. 3, pp. 461-470, 1987.

[85] J. Wu and R. J. Kaufman, "From acute ER stress to physiological roles of the unfolded protein response," Cell Death and Differentiation, vol. 13, no. 3, pp. 374-384, 2006.

[86] A. T. Sage, L. A. Walter, Y. Shi et al., "Hexosamine biosynthesis pathway flux promotes endoplasmic reticulum stress, lipid accumulation, and inflammatory gene expression in hepatic cells," American Journal of Physiology, vol. 298, no. 3, pp. E499-E511, 2010.

[87] J. N. Lee and J. Ye, "Proteolytic activation of sterol regulatory element-binding protein induced by cellular stress through depletion of Insig-1," The Journal of Biological Chemistry, vol. 279, no. 43, pp. 45257-45265, 2004.

[88] G. H. Werstuck, S. R. Lentz, S. Dayal et al., "Homocysteineinduced endoplasmic reticulum stress causes dysregulation of the cholesterol and triglyceride biosynthetic pathways," The Journal of Clinical Investigation, vol. 107, no. 10, pp. 1263-1273, 2001.

[89] I. Tabas and D. Ron, "Integrating the mechanisms of apoptosis induced by endoplasmic reticulum stress," Nature Cell Biology, vol. 13, no. 3, pp. 184-190, 2011.

[90] U. Özcan, Q. Cao, E. Yilmaz et al., "Endoplasmic reticulum stress links obesity, insulin action, and type 2 diabetes," Science, vol. 306, no. 5695, pp. 457-461, 2004.

[91] D. A. Cunha, P. Hekerman, L. Ladrière et al., "Initiation and execution of lipotoxic ER stress in pancreatic $\beta$-cells," Journal of Cell Science, vol. 121, no. 14, pp. 2308-2318, 2008.

[92] Y. Li, R. F. Schwabe, T. DeVries-Seimon et al., "Free cholesterol-loaded macrophages are an abundant source of tumor necrosis factor- $\alpha$ and interleukin-6: model of NF$\kappa \mathrm{B}$ - and map kinase-dependent inflammation in advanced atherosclerosis," The Journal of Biological Chemistry, vol. 280, no. 23, pp. 21763-21772, 2005.

[93] F. Ursini, K. J. A. Davies, M. Maiorino, T. Parasassi, and A. Sevanian, "Atherosclerosis: another protein misfolding disease?" Trends in Molecular Medicine, vol. 8, no. 8, pp. 370374, 2002.

[94] M. Vasa-Nicotera, "The new kid on the block: the unfolded protein response in the pathogenesis of atherosclerosis," Cell Death and Differentiation, vol. 11, no. 1, pp. S10-S11, 2004.

[95] J. Zhou, S. Lhotak, B. A. Hilditch, and R. C. Austin, "Activation of the unfolded protein response occurs at all stages of atherosclerotic lesion development in apolipoprotein Edeficient mice," Circulation, vol. 111, no. 14, pp. 1814-1821, 2005.

[96] S. M. Colgan, D. Tang, G. H. Werstuck, and R. C. Austin, "Endoplasmic reticulum stress causes the activation of sterol regulatory element binding protein-2," International Journal of Biochemistry and Cell Biology, vol. 39, no. 10, pp. 18431851, 2007.

[97] H. Shimano, J. D. Horton, R. E. Hammer, I. Shimomura, M. S. Brown, and J. L. Goldstein, "Overproduction of cholesterol and fatty acids causes massive liver enlargement in transgenic mice expressing truncated SREBP-1a," The Journal of Clinical Investigation, vol. 98, no. 7, pp. 1575-1584, 1996.

[98] H. L. Pahl and P. A. Baeurle, "A novel signal transduction pathway from the endoplasmic reticulum to the nucleus is mediated by transcription factor NF- $\kappa \mathrm{B}$," The EMBO Journal, vol. 14, no. 11, pp. 2580-2588, 1995.

[99] H. Y. Jiang, S. A. Wek, B. C. McGrath et al., "Phosphorylation of the $\alpha$ subunit of eukaryotic initiation factor 2 is required for activation of NF- $\kappa \mathrm{B}$ in response to diverse cellular stresses," Molecular and Cellular Biology, vol. 23, no. 16, pp. 5651-5663, 2003.

[100] A. J. Kim, Y. Shi, R. C. Austin, and G. H. Werstuck, "Valproate protects cells fom ER stress-induced lipid accumulation and apoptosis by inhibiting glycogen synthase kinase-3," Journal of Cell Science, vol. 118, no. 1, pp. 89-99, 2005.

[101] G. S. Hossain, J. V. Van Thienen, G. H. Werstuck et al., "TDAG51 is induced by homocysteine, promotes detachment-mediated programmed cell death, and contributes to the development of atherosclerosis in hyperhomocysteinemia," The Journal of Biological Chemistry, vol. 278, no. 32, pp. 30317-30327, 2003.

[102] R. Ross, "Atherosclerosis - an inflammatory disease," The New England Journal of Medicine, vol. 340, no. 2, pp. 115126, 1999.

[103] A. J. Lusis, "Atherosclerosis," Nature, vol. 407, no. 6801, pp. 233-241, 2000.

[104] W. Qiu, R. Kohen-Avramoglu, S. Mhapsekar, J. Tsai, R. C. Austin, and K. Adeli, "Glucósamine-induced endoplasmic reticulum stress promotes apoB100 degradation: evidence for Grp78-mediated targeting to proteasomal degradation," Arteriosclerosis, Thrombosis, and Vascular Biology, vol. 25, no. 3, pp. 571-577, 2005.

[105] L. Rossetti, M. Hawkins, W. Chen, J. Gindi, and N. Barzilai, "In vivo glucosamine infusion induces insulin resistance in normoglycemic but not in hyperglycemic conscious rats," The Journal of Clinical Investigation, vol. 96, no. 1, pp. 132140, 1995.

[106] G. A. Raciti, C. Iadicicco, L. Ulianich et al., "Glucosamineinduced endoplasmic reticulum stress affects GLUT4 expression via activating transcription factor 6 in rat and human skeletal muscle cells," Diabetologia, vol. 53, no. 5, pp. 955965, 2010.

[107] T. P. Ciaraldi, L. Carter, S. Nikoulina, S. Mudaliar, D. A. McClain, and R. R. Henry, "Glucosamine regulation of glucose metabolism in cultured human skeletal muscle cells: divergent effects on glucose transport/phosphorylation and glycogen synthase in non-diabetic and type 2 diabetic subjects," Endocrinology, vol. 140, no. 9, pp. 3971-3980, 1999.

[108] H. Chen, B. L. Ing, K. A. Robinson, A. C. Feagin, M. G. Buse, and M. J. Quon, "Effects of overexpression of glutamine:fructose-6-phosphate amidotransferase (GFAT) and glucosamine treatment on translocation of GLUT4 in rat adipose cells," Molecular and Cellular Endocrinology, vol. 135, no. 1, pp. 67-77, 1997.

[109] M. Federici, R. Menghini, A. Mauriello et al., "Insulindependent activation of endothelial nitric oxide synthase is impaired by O-linked glycosylation modification of signaling 
proteins in human coronary endothelial cells," Circulation, vol. 106, no. 4, pp. 466-472, 2002.

[110] M. G. Wallis, M. E. Smith, C. M. Kolka et al., "Acute glucosamine-induced insulin resistance in muscle in vivo is associated with impaired capillary recruitment," Diabetologia, vol. 48, no. 10, pp. 2131-2139, 2005.

[111] T. Monauni, M. G. Zenti, A. Cretti et al., "Effects of glucosamine infusion on insulin secretion and insulin action in humans," Diabetes, vol. 49, no. 6, pp. 926-935, 2000.

[112] R. Muniyappa, R. J. Karne, G. Hall et al., "Oral glucosamine for 6 weeks at standard doses does not cause or worsen insulin resistance or endothelial dysfunction in lean or obese subjects," Diabetes, vol. 55, no. 11, pp. 3142-3150, 2006.

[113] R. R. Simon, V. Marks, A. R. Leeds, and J. W. Anderson, "A comprehensive review of oral glucosamine use and effects on glucose metabolism in normal and diabetic individuals," Diabetes/Metabolism Research and Reviews, vol. 27, no. 1, pp. 14-27, 2011.

[114] A. J. Bowes, M. I. Khan, Y. Shi, L. Robertson, and G. H. Werstuck, "Valproate attenuates accelerated atherosclerosis in hyperglycemic ApoE-deficient mice: evidence in support of a role for endoplasmic reticulum stress and glycogen synthase kinase-3 in lesion development and hepatic steatosis," American Journal of Pathology, vol. 174, no. 1, pp. 330-342, 2009.

[115] D. R. Beriault, S. Sharma, Y. Shi, M. I. Khan, and G. H. Werstuck, "Glucosamine-supplementation promotes endoplasmic reticulum stress, hepatic steatosis and accelerated atherogenesis in apoE-/- mice," Atherosclerosis, vol. 219, no. 1, pp. 134-140, 2011.

[116] L. R. Tannock, E. A. Kirk, V. L. King, R. LeBoeuf, T. N. Wight, and A. Chait, "Glucosamine supplementation accelerates early but not late atherosclerosis in LDL receptor-deficient mice," Journal of Nutrition, vol. 136, no. 11, pp. 2856-2861, 2006.

[117] P. Prasad, A. K. Tiwari, K. M. P. Kumar et al., "Association analysis of ADPRT1, AKR1B1, RAGE, GFPT2 and PAI-1 gene polymorphisms with chronic renal insufficiency among Asian Indians with type-2 diabetes," BMC Medical Genetics, vol. 11, no. 1, article 52, 2010.

[118] D. R. Laybutt, A. M. Preston, M. C. Akerfeldt et al., "Endoplasmic reticulum stress contributes to beta cell apoptosis in type 2 diabetes," Diabetologia, vol. 50, no. 4, pp. 752-763, 2007.

[119] P. Marchetti, M. Bugliani, R. Lupi et al., "The endoplasmic reticulum in pancreatic beta cells of type 2 diabetes patients," Diabetologia, vol. 50, no. 12, pp. 2486-2494, 2007.

[120] M. Igoillo-Esteve, L. Marselli, D. A. Cunha et al., "Palmitate induces a pro-inflammatory response in human pancreatic islets that mimics CCL2 expression by beta cells in type 2 diabetes," Diabetologia, vol. 53, no. 7, pp. 1395-1405, 2010.

[121] U. Özcan, E. Yilmaz, L. Özcan et al., "Chemical chaperones reduce ER stress and restore glucose homeostasis in a mouse model of type 2 diabetes," Science, vol. 313, no. 5790, pp. 1137-1140, 2006.

[122] W. J. Welch and C. R. Brown, "Influence of molecular and chemical chaperones on protein folding," Cell Stress and Chaperones, vol. 1, no. 2, pp. 109-115, 1996.

[123] Q. Xie, V. I. Khaoustov, C. C. Chung et al., "Effect of tauroursodeoxycholic acid on endoplasmic reticulum stressinduced caspase-12 activation," Hepatology, vol. 36, no. 3, pp. 592-601, 2002.
[124] E. Erbay, V. R. Babaev, J. R. Mayers et al., "Reducing endoplasmic reticulum stress through a macrophage lipid chaperone alleviates atherosclerosis," Nature Medicine, vol. 15, no. 12, pp. 1383-1391, 2009.

[125] H. Tsukano, T. Gotoh, M. Endo et al., "The endoplasmic reticulum stress-C/EBP homologous protein pathwaymediated apoptosis in macrophages contributes to the instability of atherosclerotic plaques," Arteriosclerosis, Thrombosis, and Vascular Biology, vol. 30, no. 10, pp. 1925-1932, 2010.

[126] E. Thorp, G. Li, T. A. Seimon, G. Kuriakose, D. Ron, and I. Tabas, "Reduced apoptosis and plaque necrosis in advanced atherosclerotic lesions of Apoe-/- and Ldlr-/mice lacking CHOP," Cell Metabolism, vol. 9, no. 5, pp. 474481, 2009.

[127] M. G. Buse, "Hexosamines, insulin resistance, and the complications of diabetes: current status," American Journal of Physiology, vol. 290, no. 1, pp. E1-E8, 2006.

[128] P. Durand, B. Golinelli-Pimpaneau, S. Mouilleron, B. Badet, and M.-A. Badet-Denisot, "Highlights of glucosamine-6P synthase catalysis," Archives of Biochemistry and Biophysics, vol. 474, no. 2, pp. 302-317, 2008.

[129] B. W. Doble and J. R. Woodgett, "GSK-3: tricks of the trade for a multi-tasking kinase," Journal of Cell Science, vol. 116, no. 7, pp. 1175-1186, 2003.

[130] G. H. Werstuck, A. J. Kim, T. Brenstrum, S. A. Ohnmacht, E. Panna, and A. Capretta, "Examining the correlations between GSK-3 inhibitory properties and anti-convulsant efficacy of valproate and valproate-related compounds," Bioorganic and Medicinal Chemistry Letters, vol. 14, no. 22, pp. 5465-5467, 2004.

[131] Y. Shi, D. Gerritsma, A. J. Bowes, A. Capretta, and G. H. Werstuck, "Induction of GRP78 by valproate is dependent upon histone deactylase inhibition," Bioorganic \& Medicinal Chemistry Letters, vol. 17, no. 16, pp. 4491-4494, 2007.

[132] I. Partserniak, G. Werstuck, A. Capretta, and J. D. Brennan, "An ESI-MS/MS method for screening of small-molecule mixtures against glycogen synthase kinase-3 $\beta$ (GSK-3 $\beta$ )," ChemBioChem, vol. 9, no. 7, pp. 1065-1073, 2008. 


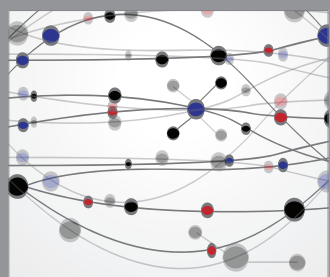

The Scientific World Journal
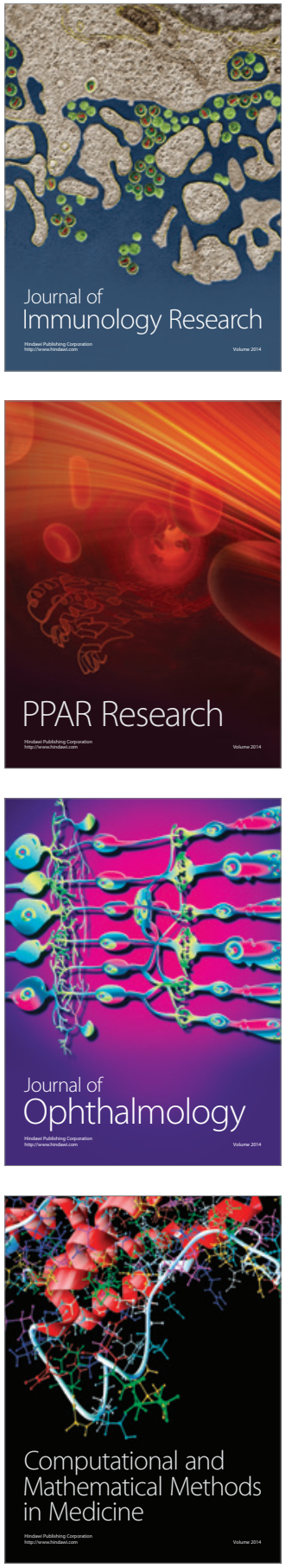

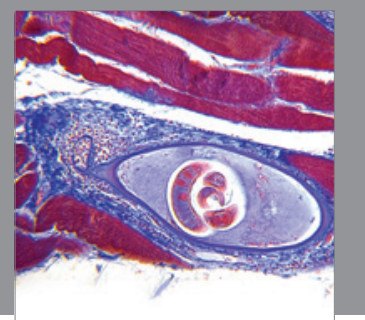

Gastroenterology

Research and Practice
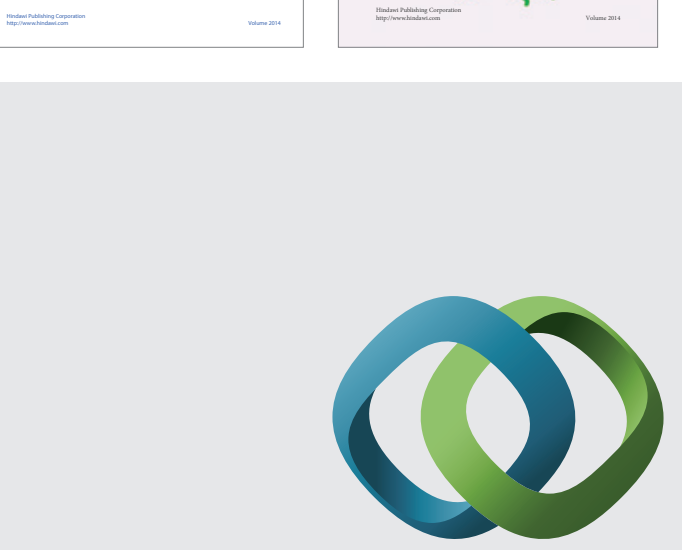

\section{Hindawi}

Submit your manuscripts at

http://www.hindawi.com
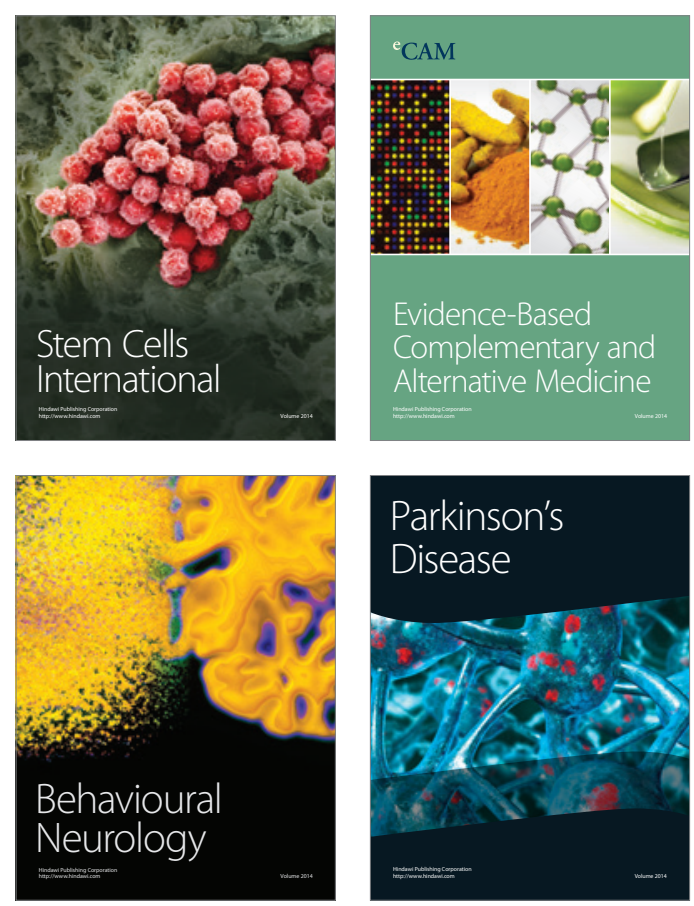

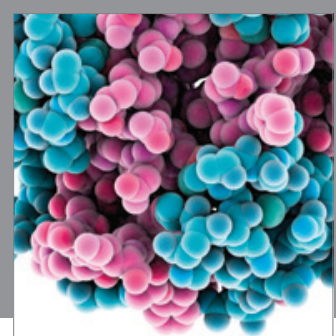

Journal of
Diabetes Research

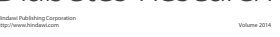

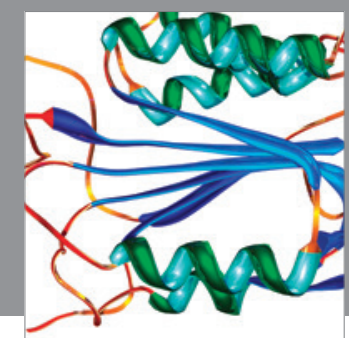

Disease Markers
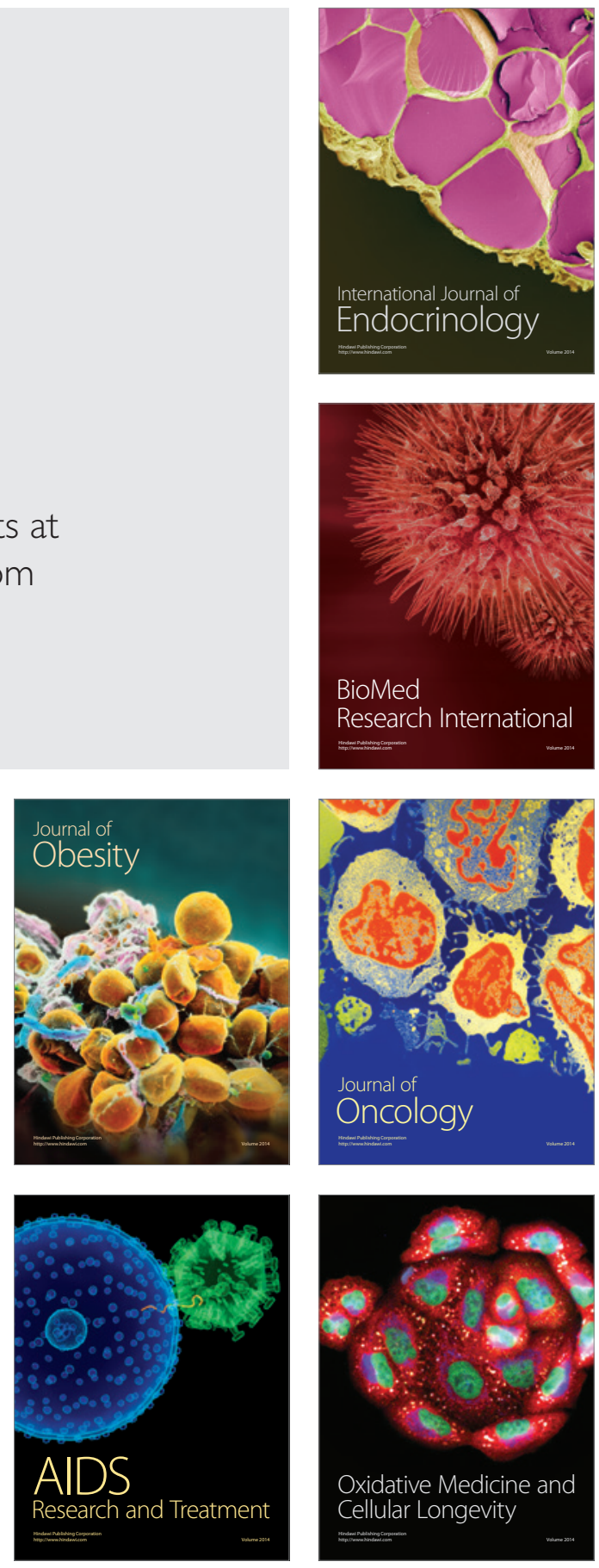